Manuscript version 7 September 2012

RUNNING HEAD： PSYCHO-SOCIAL DETERMINANTS OF PUBLIC TRANSPORT USE

\title{
Defining the psycho-social determinants of public transport use: An integrated theoretical approach
}

\author{
Camilla Morley $^{1} \quad$ Taciano L. Milfont ${ }^{2} \quad$ Sophie Bond ${ }^{1}$ \\ ${ }^{1}$ School of Geography, Environment and Earth Sciences, \\ Victoria University of Wellington, New Zealand \\ ${ }^{2}$ School of Psychology, Victoria University of Wellington, New Zealand
}

AUTHORS' NOTE: This study was submitted as part of Camilla Morley's Master's thesis to Victoria University of Wellington, completed under the supervision of Sophie Bond and Taciano L. Milfont. Correspondence concerning this article should be addressed to Taciano L. Milfont, who is now at the School of Psychology, University of Waikato, New Zealand. E-mail:

taciano.milfont@waikato.ac.nz / www.milfont.com. 
Psycho-social determinants of public transport use 1

\begin{abstract}
Car use is engrained in our culture. Changing behaviour towards using more sustainable travel modes such as public transport is notoriously difficult, despite the increasing awareness of environmental problems caused by car use. Many models have attempted to explain what psychological constructs activate pro-environmental behaviour. Models often adopt either an altruistic approach to pro-environmental behaviour such as Ajzen's theory of planned behaviour, or a pro-social approach using Schwartz's norm-activation model, or Stern et al.'s value-beliefnorm theory. This research tests the psychological constructs determining decisions to use public transport using an integrated environmental behaviour model recently proposed by Bamberg and Möser. The results support the integrated modelling approach. Intentions to use public transport are indirectly affected by awareness of environmental problems caused by car use mediated through social norms, guilt, perceived behavioural control and attitude. Intention to use public transport explains $56 \%$ of the variance in self-reported public transport behaviour. Theoretical and practical implications are discussed.
\end{abstract}

Keywords: Public transport, Travel mode choice, Pro-environmental behaviour, Norm-activation model, Theory of planned behaviour, Value belief norm theory 


\section{Introduction}

The car is the dominant form of transport in urban areas; yet car use creates many negative effects on the environment and society. These negative effects include accidents, air and noise pollution and associated health problems (see Fisher et al., 2002) as well as environmental degradation, threatening long-term oil availability and climate change (IPCC, 2007). Car use is recognised worldwide as a social dilemma and a complex policy problem (Joireman, Van Lange, \& Van Vugt, 2004). A social dilemma arises when a person is confronted with a choice between acting in a way that will benefit him or herself but has negative consequences for a group of others. Alternatively, when modelled in a positive way, a social dilemma can occur when one acts in a way that removes some of the immediate benefits to themselves but produces a collective common good (Dawes \& Messick, 2000; Ostrom, 2000). Car use causes a social dilemma because for the individual it provides mobility, comfort and independence but there are negative consequences for the collective.

As with many solutions to environmental problems that are caused by human actions, a solution to reducing car use relies on changing human behaviour (Staats, 2004). Public transport systems offer a more sustainable travel mode choice over the car (May, Kelly, \& Shepherd, 2006; Shapiro, Hassett, \& Arnold, 2002). However, changing behaviour away from car use and towards more sustainable travel modes, such as public transport, is notoriously difficult. A number of barriers to behaviour change exist including both structural barriers (physical surroundings, institutional governance and cultural traditions) and psychological barriers (cognitive dissonance, cognitive biases, reactance and habit) (see Milfont, 2010; Milfont, Abrahamse \& McMarthy, 2011; Swim et al., 2009). The negative consequences of car use and the difficulties associated with mode switching has meant that reducing car use has been the 
focus of many social, economic, environmental and policy studies (e.g., Brög, Erl, \& Mense, 2004; Jakobsson, Fujii, \& Gärling, 2002; Johansson, Heldt, \& Johansson, 2006). Environmental and social psychological research is developing this area by distinguishing which underlying psychological constructs lead to pro-environmental behaviour.

This study expands on previous research that identifies the psycho-social variables associated with pro-environmental behaviour, specifically for public transport use. Psycho-social variables include those that are related to personal perceptions and attitudes towards taking public transport instead of the car for everyday trips. The objectives of the present study are twofold. The first is to build on previous integrated modelling research (Bamberg \& Möser, 2007; Klöckner \& Blöbaum, 2010; Peters, et al., 2011) to better understand the relationship of the psychological constructs leading towards pro-environmental behaviour, and more specifically intentions to use public transport for those who also have the option to drive (Bamberg, et al., 2007). The second objective is to assess whether intention to use public transport leads to actual public transport use as postulated in the theory of planned behaviour (Ajzen, 1991). Two models proposed by Bamberg and Möser (2007) and Bamberg, et al. (2007) are tested.

The overall aim of this study is thus to confirm that the integrated model approach based on the theoretical assumptions identified in the literature review below - effectively helps to explain decisions to use public transport over the car in Greater Wellington, New Zealand. The Greater Wellington region has a high use of public transport compared with other regions; yet driving remains the dominant form of transport with $68 \%$ of trips to work taken by car (GWRC, 2010). The rationale is that an understanding of the psychological constructs will be useful in the design of, and understanding the reactions to, interventions aimed at changing behaviour in favour of public transport over the car. The paper starts by outlining some key 
theories in pro-environmental behaviour and reviewing studies which focus on travel mode choice. The two integrated behaviour models tested in this study are then introduced and explained. The theoretical and practical outcomes of the study as well as suggestions for future research are also presented.

\section{Theoretical models used to explain pro-environmental behaviour}

Pro-environmental behaviour research focuses on the intent to change behaviour that affects the environment. Research in this domain has been motivated by two main areas of thought which are broadly in line with the social dilemma theory. The first main area of thought argues that pro-environmental behaviour is encouraged by pro-social interests (acting in the interests of society and/or the environment). Researchers tend to use Schwartz's (1977) normactivation model (NAM), or similarly Stern, Dietz, Abel, Guagnano and Kalof's (1999) valuebelief-norm theory (VBN) to explain pro-environmental behaviour in terms of pro-social interests (e.g., De Groot \& Steg, 2009; Milfont, Sibley \& Duckitt, 2010; Steg, Dreijerink, \& Abrahamse, 2005). According to these theories pro-environmental behaviour is attributed to an awareness of environmental problems and feelings of moral obligation (personal norms) to act in favour of the environment. The second main area of thought focuses on self-interests (acting to minimise personal costs and risks), and often uses Ajzen's (1991) theory of planned behaviour (TPB) to explain pro-environmental behaviour (e.g., Boldero, 1995; Kaiser \& Gutscher, 2003; Lake, Milfont \& Gavin, in press). According to the TPB, subjective norms, attitudes and perceived behavioural control are the main determinants of intentions to act in a proenvironmental manner, and intention is in turn the main determinant of actual behaviour. Subjective norm, also called social norm, is the actor's perceived influence from society to behave in a certain way. Attitudes encompass the positive or negative values placed on the given 
behaviour by the actor, and perceived behavioural control is the extent to which the actor perceives s/he can carry out the behaviour with all available resources and capabilities.

The NAM and TPB are the most common theories used to explain pro-environmental behaviour in environmental psychology (Staats, 2004). In the context of car use it would follow that people who were solely concerned in maximising their own well-being would be more likely to drive, compared to those who demonstrated pro-social attitudes who would be more likely to take public transport because it is better for the environment and society as a whole. Consequently the TPB would better explain car use than the NAM. Whilst there is some evidence to suggest that this is the case (Joireman, et al., 2004; Van Vugt, Meertens \& van Lange, 1995) in reality motivations for pro-environmental behaviour may be for both pro-social or self-interest reasons due to the importance of context (cost, time and convenience factors). Thus, both reasons should be accounted for in an attempt to understand people's motivations for using sustainable travel modes.

Furthermore, pro-environmental behaviour is complex. Therefore, it has been suggested that using one theory or model to explain pro-environmental behaviour will not suffice (Kaiser, 2006; Stern, 2000; Wall, Devine-Wright, \& Mill, 2007). In the transport domain studies are combining models to attempt to explain which variables motivate sustainable travel mode choices (Abrahamse, Steg, Gifford, \& Vlek, 2009; Bamberg \& Schmidt, 2003; Heath \& Gifford, 2002; Hunecke, Blobaum, Matthies, \& Hoger, 2001). The conclusive result is that constructs mainly from the NAM and TPB are influential in predicting travel mode choice, although often to different extents. For instance, Abrahamse et al. (2009) found that the main predictors of car use for commuting purposes were explained by attitude and perceived behavioural control, which are self-interest variables as postulated in the TPB. In contrast, the authors found that 
intention to reduce car use was mainly explained by personal norms, as suggested in the NAM. Social norm was not a significant predictor of car use or intentions to reduce it. They suggest that whilst both types of variables (self-interest and moral/pro-social) are important in predicting behavioural outcomes they may be useful in predicting different types of behaviour. Self-interest variables better explain choices that have high individual costs, such as driving to work, whereas willingness to reduce car use may be more affected by moral considerations, especially where perceived behavioural control is weak (Abrahamse, et al., 2007; Van Vugt et al. 1995).

In sum, the extant research on travel mode choice suggests that the NAM and TPB variables should be integrated. Indeed, Wall et al. (2007) found that the NAM variables were better predictors of intention to reduce car use than the TPB variables in a study of university students in England. However, when the models were integrated the explained variance of intention to reduce car use increased. Although personal norm and perceived behavioural control were the only significant predictors of intention, their findings support the notion that neither the NAM or TPB models by themselves fully capture travel mode behaviour. The authors also acknowledge the importance of external factors which are not explained by either the NAM or TPB. For example, other factors such as habit (Verplanken et al., 1998), social demographics (Matthies et al., 2002) and physical context (Limtanakool et al., 2006) have also been shown to influence travel behaviour.

Another study trying to integrate different variables was reported by Hunecke et al. (2001) who modified the NAM to explain subway use in Bochum, Germany. They added social norm, a variable from the TPB, and external costs (by offering a free public transport ticket) to the NAM. Personal norm and external costs were found to be the most influential predictors of subway use. Personal norm was mediated through the NAM variables as well as social norm. 
Conversely, a separate study combining the NAM, TPB and Triandis' theory of interpersonal behaviour $^{1}$, found that personal norms were not a contributing factor in influencing intention or behaviour to reduce car use amongst tertiary students in Giessen, Germany (Bamberg \& Schmidt, 2003). The authors argued that this outcome could be expected in view of the social acceptability of car use and general personal advantages (convenience, time) of the car over proenvironmental modes such as public transport.

The research reviewed above shows that distinct variables have differing effects on travel mode behaviour. The disparities in research findings may be due to place, culture or context, but also highlight the role of wider influencing factors on intention and behaviour, including external factors such as cost. Whilst it is acknowledged that external factors have a definite role to play in travel mode decisions, the focus of this paper is to assess the role of socio-psychological factors in decisions to use public transport. There is clear evidence from the literature that a combination of variables from the NAM (mainly personal norm) and from the TPB (mainly attitude and perceived behavioural control) exert a combined influence on travel mode choices.

\section{An integrated theoretical approach}

Research has long recognised that a diverse number of variables lead to proenvironmental behaviour, but the extent of each variable's influence on pro-environmental behaviour had not been quantitatively defined until the paper by Hines, Hungerford and Tomera (1986/7). Their study comprised of a meta-analysis of research reporting pro-environmental behaviour since 1971. Their meta-analytical review identified three groups of variables that had

\footnotetext{
${ }^{1}$ Triandis' (1997) theory of interpersonal behaviour is similar to Ajzen's TPB except that habit is included as a predictor of intention (see Bamberg and Schmidt, 2003).
} 
been reported to influence pro-environmental behaviour: cognitive, psycho-social and demographic variables. The demographic variables, including age, income, education and gender, were found to be weakly correlated, or not at all correlated, to pro-environmental behaviour. Cognitive variables were based on knowledge of the environment and environmental issues. There was a positive correlation between knowledge of environmental issues and proenvironmental behaviour. The psycho-social variables included personal attitudes and perceptions of environmental behaviour. The authors found that attitudes, locus of control (similar to perceived behavioural control), verbal commitments and an individual's sense of responsibility were all positively related to pro-environmental behaviour. Overall, they found that three psycho-social variables (verbal commitment, locus of control, and attitudes) were the most important variable associated with pro-environmental behaviour. The authors proposed a model of responsible environmental behaviour including the cognitive and psycho-social variables found to be relevant from the meta-analysis, which are mediated through intentions to act as stipulated in Ajzen's (1991) TPB. Hines et al. (1986/7) also included situational factors in their model to account for economic and cultural constraints on acting in a pro-environmental manner.

The Hines et al. (1986/7) research was ahead of its time in suggesting that both pro-social and self-interest variables influence pro-environmental behaviour. Whilst recent studies have integrated components of the NAM and TPB to explain pro-environmental behaviour, few have taken the holistic approach promoted by Hines et al. (1986/7). This research gap was identified by Bamberg and Möser (2007) who updated the Hines et al. study by conducting a meta-analytic structural equation model (MASEM) to test the psycho-social variables as depicted in Figure 1. A total of 46 studies, which reported 57 samples, were used for the MASEM. The variables 
within the model are similar to those suggested by Hines et al. (1986/7). The Bamberg and Möser model includes environmental awareness, attitudes, locus of control (identified as perceived behavioural control in Figure 1), and personal responsibility (identified by the guilt and moral norm variables). Situational factors are also partly captured within social norms. Although, the model does not specifically account for economic considerations, it could be argued that the variable perceived behavioural control does capture some economic constraints.

[Figure 1 about here]

In line with Hines et al. (1986/7) and the TPB, the psycho-social variables influencing pro-environmental behaviour in Figure 1 are mediated through intention, which explained 27\% of the variance of behaviour. In contrast to the TPB, but as suggested in previous studies (Hunecke, et al., 2001; Wall, et al., 2007), the NAM variable personal norm was found to be a direct predictor of intention alongside the TPB variables perceived behavioural control and attitude. Perceived behavioural control was the strongest predictor of intention $(\beta=0.31)$ compared to attitude and person norm ( $\beta=0.29$ for both). The VBN variable problem awareness indirectly affected pro-environmental behaviour, influencing social norms, internal attribution (awareness of consequences), guilt and personal norm. The model by Bamberg and Möser (2007) thus provides both a comprehensive theoretical and empirical review of the NAM, VBN and TPB variables.

A model similar to that proposed by Bamberg and Möser (2007) has since been tested in transportation research. Bamberg et al. (2007) used the model primarily to test the influence of social context and personal norms on intentions to use public transport in two regions in Germany. The Bochum/Dortmund region is illustrative of a traditional industrial society where there are perhaps favourable attitudes towards car use viewed as a vehicle for economic 
prosperity. In contrast, Frankfurt can be described as post-industrial where modern values go beyond material wealth and car use is associated with negative consequences on the environment and society. They first tested a modified NAM before adding the TPB variables. Therefore, the pathways linking the constructs differ slightly to the model shown in Figure 1. The differences are: no link between problem awareness and awareness of consequences (internal attribution); a direct link between problem awareness and guilt, instead of with personal norm; and no link between guilt and perceived behavioural control or attitude, but linking guilt and intention directly. The inclusion of the TPB variables drastically increased the predictive power of the model for the Bochum/Dortmund area from 3\% to 20\%, and for Frankfurt from $36 \%$ to $54 \%$. As hypothesised, the authors found that the strength of the variables' influence on intention were quite different in the two regions studied. In Bochum/Dortmund, attitude $(\beta=0.35)$ was the strongest predictor of intention, followed by personal norm $(\beta=0.20)$ and perceived behavioural control $(\beta=0.19)$. However, in Frankfurt perceived behavioural control $(\beta=0.57)$ was the strongest predictor of intention, followed by personal norm $(0.40)$ and attitude $(\beta=0.17)$, highlighting the importance of culture and context when assessing complex pro-environmental behaviours.

Overall, Bamberg et al. (2007) found that personal norm was a direct predictor of intention to use public transport which was largely affected by social norms, substantiating the re-positioning of these two constructs in contrast to the TPB. All variables were significant in the integrated model, apart from the path between awareness of consequences and social norm. They also assessed the affect of past behaviour to see whether public transport habits strongly influence actual behaviour as suggested in the literature (Bamberg \& Schmidt, 2003; Eriksson, Garvill, \& Nordlund, 2008; Verplanken, Aarts, van Knippenberg, \& Moonen, 1998). The 
inclusion of habit as a predictor of public transport use increased the Frankfurt model's explanatory strength by $27 \%$ (the Bochum/Dortmund model was not tested due to lack of data on past behaviour).

A more recent study on the purchase of fuel-efficient vehicles also adapted the Bamberg and Möser (2007) model (Peters, Gutscher, \& Scholz, 2011). The authors found that attitude, perceived behavioural control and personal norm were direct predictors of decisions to buy fuelefficient vehicles. These three predictors of intention were influenced by social norms and response efficacy (a person's belief about the consequences of their actions which is identified as awareness of consequences in the NAM), and were indirectly influenced by problem awareness. Thus, there is evidence to suggest that whilst the variables from either the pro-social or selfinterest motivated models have value in explaining pro-environmental behaviour individually, the integrated behaviour model proposed by Bamberg and Möser (2007) is theoretically superior in explaining the link between pro-environmental intention and behaviour in transportation research.

\section{The present research}

The present research formed part of wider research on travel behaviour and perceptions towards public transport for the Greater Wellington region in New Zealand (see Morley, 2011). Greater Wellington is divided into eight main territorial authorities that have a total population of around 450,000. The region is serviced by bus, rail and ferry and has the highest use of public transport compared with other regions in New Zealand. However, driving remains the dominant form of transport. The regional council has a target to increase the number of public transport trips at peak times (morning and evening commuting times) by $32 \%$, from 17.4 million peak trips estimated in 2009/10 to 23 million per annum by 2020 (GWRC, 2010). This will be no easy 
feat as recent public perception surveys indicate that trust in the public transport system is very low (Morley, 2011; Premium Research, 2010).

The goal of the present study is to asses what psycho-social variables affect public transport use, which is taken as an example of pro-environmental behaviour, and has two main objectives. Through objective one, modelling research is expanded upon to better understand the relationship of the variables influencing public transport use. Objective two assesses the effect of intention as a mediating variable to behaviour, as suggested in the TPB. Based on extant research, it was expected that both pro-social and self-interest variables would be significant in predicting public transport use. Perceived behavioural control, attitude and personal norm are predicted to have a direct influence on intention. In line with the TPB the psycho-social variables were mediated through intention and there was expected to be a positive relationship between intention and self-reported public transport use.

\section{Method}

\section{Data collection and participants}

An online survey was used to collect data amongst residents of the Greater Wellington region. Online surveys are increasingly used to collect data in a variety of academic, corporate and political fields (Manfreda \& Vehovar, 2008; Reips, 2006). Reviews on the effectiveness of online surveys compared with traditional paper or telephone surveys are mixed and will differ from study to study (Parsons, 2007; Riva, Teruzzi \& Anolli, 2003). Nevertheless, a benefit over paper surveys is the ability to cover a large geographic area with little to no cost. This was crucial to the current research which covered the entire Greater Wellington region: about 3000 square miles. The limitations of online surveys, mainly being accessible to computer literate persons only, was acknowledged. However, considering the sample size was relatively large (see 
below) and the effect of demographic variables on pro-environmental behaviour have been shown to be relatively weak (Hines, et al., 1986/7), the method was justified. The survey was confidential and anonymous.

The research assessed pro-environmental intentions to use public transport rather than to drive. Therefore, only participants that indicated they drove for everyday trips (to work/study, to go food shopping, or to get to leisure or sporting activities) within Greater Wellington were directed to the specific set of survey questions measuring pro-environmental intention and behaviour. A total of 370 participants indicated they drove for everyday trips, of which 359 participants completed at least three quarters of the questions measuring the psychological constructs used in the model. The sample's characteristics are shown in Table 1 alongside a regional benchmark when available. The sample was somewhat older, and overrepresented males and participants from Wellington city, but overall was comparable to the population of the region.

[Table 1 about here]

\section{Measures}

To understand how pro-environmental intentions are formed, and how they lead towards behaviour, a number of questions/items were used to capture the latent constructs used in the environmental behaviour model. These measures closely followed those used in the Bamberg et al. (2007) study, but some new items were also developed. To ensure the constructs are adequately captured and consistent, and to reduce the instances of common method variance arising from self-reported measures, at least three items were used for each construct (Diamantopoulos \& Siguaw, 2000). Also expanding previous studies, one item for each construct was reverse scored to reduce direction-of-wording effects (indicated by an asterisk sign in Table 
2). To reduce bias in response pattern, questions were randomized for each survey participant, which is another advantage of online surveys. An initial pool of questions was piloted two months before the final survey was launched amongst 41 participants. Feedback provided during this process was fundamental to the redesign of the final survey which was simplified and shortened.

The final questions/items used are presented in Table 2 and most were answered on a 5point scale (anchored by $1=$ strongly disagree and $5=$ strongly agree; unless otherwise indicated in Table 2), where a higher score indicated a more favourable response. Additionally, selfreported behaviour was measured by three separate questions. To reduce any cognitive dissonance arising from the self-reporting behaviour measures, two out of the three measures were asked at the beginning of the survey, followed by wider questions on travel and then the remaining questions measuring the latent constructs.

Internal validity as indicated by Cronbach's alphas is also presented in Table 2. All measures had Cronbach's alphas higher than 0.7 which indicated good internal validity, except for the social norm scale which had an alpha of 0.52 and also had weak psychometric properties in the pilot study. This scale was kept in the subsequent analyses for several reasons. It has been suggested that in studies with a large number of participants (over 100) Cronbach's alpha values of 0.4 (Mueller, 1986) or 0.5 (Field, 2000) are acceptable (see also Hooper \& Zhou, 2007), and the alpha in the present study was not too low (below 0.3) to reject completely (Pallant, 2010). Finally, and perhaps most importantly, social norms were identified to be influential in determining pro-environmental outcomes through the TPB and various modified versions (e.g., Harland, Staats, \& Wilke, 1999; Wall, et al., 2007). Therefore, the social norm construct was retained to align with the integrated environmental behaviour model. 
[Table 2 about here]

\section{Results}

\section{Mean values of the measures}

To provide an overview of how survey participants responded to the measures, the mean score for each psychological construct leading to behaviour was computed and one-sample $t$-tests were calculated to compare the mean scores to the scale mid-point. The results are shown in Table 3 .

[Table 3 about here]

Problem awareness and awareness of consequences show mean scores significantly different from the scale mid-point, indicating that respondents believe car use is an environmental problem and acknowledge that their car use causes both social and environmental damages. Respondents also felt that they have control in deciding to take public transport for everyday trips in Greater Wellington, shown by the mean score of 3.74 for perceived behavioural control. High levels of perceived behavioural control could reflect the fact that $94 \%$ of the sample lived within $1 \mathrm{~km}$ of a public transport stop, but also that access to public transport in general is not perceived to be an issue. The mean score for attitude towards public transport is above the mid-point of 3 suggesting that, in general, there is a good perception of public transport in Greater Wellington. However, the mean scores for the behavioural variables are generally neutral to low, suggesting that there is a gap between intention to use public transport and actual use. The gap may be explained by some situational factors not included on the model, such as service reliability or weather. Previous studies have highlighted the importance of public transport reliability in Wellington (Premium Research 2008; 2009; 2010). In a recent survey of 559 Greater Wellington residents, 52\% indicated that public transport reliability was the most 
important factor influencing decisions to use public transport more than present levels (Morley, 2011). Finally, feelings of guilt, personal norm, social norm, and intention are within the neutral range of the scale.

\section{Test of the models}

\section{Testing the best fitting model}

A confirmatory factor analysis was conducted where standardized factor loading $(\lambda)$ shows the relationships between the items and the latent constructs. As shown in Table 4, most standardized factor loadings $(\lambda)$ were above the cut-off value of 0.5 which indicates that the measures are valid indicators of their specific constructs (Hair et al., 2006). The items PBC3 for perceived behavioural control and SN4 for social norm were much lower than 0.5 and were removed to increase reliability and decrease measurement error in the model. The item PBC4 $(\lambda$ $=0.44)$ and the behavioural question BEH2 $(\lambda=0.28)$ also had values lower than the cut-off value. However, these items were kept first so that each construct had three measuring items, which is the recommended minimum number. Second, the low $\lambda$ value for BEH2 can be explained because it is not measured on a continuous scale but is dichotomous ${ }^{2}$. Finally, there are other items measuring the construct so that the error effects are likely to be negligible (Babakus, Ferguson, \& Jöreskog, 1987).

[Table 4 about here]

Two alternative theoretical models were tested, based on the models proposed by Bamberg and Möser (2007; i.e., Model 1a in Table 5) and by Bamberg et al. (2007; i.e., Model

\footnotetext{
${ }^{2}$ The technique of reporting behavioural choices to assess pro-environmental behaviour was similarly used in a study by Cameron, Brown and Chapman (1998).
} 
2a in Table 5). Besides testing these two models, analyses were also performed to verify whether excluding non-significant paths from the models would improve model fit (i.e., Model $1 \mathrm{~b}$ and $2 \mathrm{~b}$ in Table 5). The models were tested using LISREL 8.80 with maximum-likelihood estimation, taking the observed covariance matrix as the input. The ratio of chi-square to degree of freedom $\left(\chi^{2} / \mathrm{df}\right)$, the non-normed fit index (NNFI), and the comparative fit index (CFI), the root mean square error of approximation (RMSEA), and the standardized root mean square residual (SRMR) were used to assess model fit. Models with a $\chi^{2} / \mathrm{df}$ ratio in the $2-3$ range, GFI, NNFI and CFI with values close to 0.95 , and RMSEA and SRMR with values respectively close to 0.06 and 0.08 indicate acceptable fit (Hair et al, 2006; Hu \& Bentler, 1999). The results of are shown in Table 5.

[Table 5 about here]

According to the fit criteria all of the models fit reasonably well. However, Model 1a seemed to be the preferable model because of the good fit indices as well as theoretical considerations. Model 1a was the result of a comprehensive meta-analysis by Bamberg and Möser (2007), including 46 studies with 57 independent samples and is thus theoretically and empirically superior to the Bamberg et al. (2007) model which included only 3 samples. Another deciding factor was the point of difference between the two models: the path of problem awareness predicting awareness of consequences was only empirically significant $(t=11.24)$ in Model 1a. The other points of difference between the models were non-significant, or weakly significant. The results from Model 1a are therefore theoretically and empirically more sound than the competing models.

Given the evidence given in Table 5 and discussed above, Model 1a was the model used for further analysis. The results presented thus far goes partway to answering objective one by 
providing empirical evidence that the data collected from the Greater Wellington sample fit the model proposed by Bamberg and Möser (2007). The following section analyses and discusses the relationships between the psychological constructs in the model in order to better understand the pathways.

\section{Examining the selected model}

The selected model examines how pro-environmental intentions affect public transport use. The results allow for an assessment of the constructs leading to pro-environmental intention and behaviour, as postulated in the Bamberg and Möser (2007) model. Figure 2 presents the model showing the standardised structural coefficients $(\beta)$ for each pathway and explained variances $\left(\mathrm{R}^{2}\right)$. The LISREL syntax input and covariance matrix for this model is available upon request. To assess how the model constructs affect intentions to take public transport (study objective 1), and how these intentions affect behaviour (study objective 2), the model will be discussed in parts.

The inter-correlation of the perceived behavioural control, attitude and personal norm constructs are low, between 0.06 and 0.27 . Consequently there is empirical evidence to confirm the hypothesis from the theoretical model that these three constructs are independent predictors of intention. Therefore the constructs influencing each of these three main predictors of intention are analysed and discussed. Their effect on intention to use public transport is then discussed followed by an analysis of public transport behaviour.

\section{Perceived behavioural control}

Perceived behavioural control (ease of taking public transport) was hypothesised to predict intention to take public transport and be directly affected by social norms (the extent that others' opinion of public transport affects personal public transport use) and guilt (personal guilt 
about the negative consequences of driving). The model shows that the largest effect on perceived behavioural control is from social norms $(\beta=0.34)$ and the effect of guilt is not statistically significant, suggesting that for the present sample, personal capability is more important than feelings of guilt about the environmental and social impacts of driving when deciding which mode of transport to use. Thus, social norms indirectly affect intention to use public transport for the Greater Wellington sample. The hypothesis that social norms are not direct predictors of intention, as originally postulated in the TPB, but are instead mediated by attitude and perceived behavioural control (Ajzen, 1991; Bamberg, et al., 2007; Bamberg \& Möser, 2007) is corroborated by these findings. This is further evidenced as perceived behavioural control is only to a limited extent $\left(\mathrm{R}^{2}=0.10\right)$ affected by problem awareness (awareness of global environmental problems caused by car use) mediated by social norms. The direct effect of perceived behavioural control on intention to use public transport is quite high ( $\beta$ $=0.51)$.

\section{Attitude}

Attitude towards using public transport rather than driving is the second strongest predictor of intention $(\beta=0.44)$. Therefore, as hypothesised and in line with the TPB, attitude indirectly influences behaviour to use public transport mediated through intention. A total of $41 \%$ of attitude variance is significantly explained by social norm and guilt. The formation of attitudes toward public transport is also affected by awareness of environmental problems, which is mediated by social norms and feelings of guilt. The empirical evidence therefore shows that attitudes toward taking public transport are affected by feelings of guilt about driving $(\beta=0.42)$ as well as social norms $(\beta=0.44)$, supporting the review of the original TPB model (Armitage $\&$ 
Conner, 2001). As we shall discuss below, the impact of social norms on attitude formation is important to use in policies attempting to encourage public transport use.

\section{Personal norm}

Like the influences on attitudes, the variance (95\%) in the personal norm construct can be explained by the direct influence of both social norm and guilt, and an indirect influence of problem awareness (mediated by social norm and guilt). The hypothesis that the NAM variables are not the only factors influencing personal norm is therefore confirmed, although it is acknowledged that guilt exerts the heaviest influence on personal norm $(\beta=0.90)$. However, in contrast to the NAM, awareness of consequences was not a significant direct predictor of personal norm.

Contrary to the hypothesis that personal norm predicts intention directly, the results of this study show that personal norm is not a statistically significant predictor of intention. This is not entirely unexpected considering the debate in the literature about the role of personal norm influencing intention and behaviour (Bamberg, et al., 2007; Bamberg \& Schmidt, 2003). The results for the present study show that the formation of personal norms develops from a combination of individuals having knowledge of the environmental impacts of car use plus emotional and social factors. The latter are especially characterised by feelings of guilt and social norms associated with driving versus taking public transport. Therefore, personal norm is significantly influenced by other constructs that have an indirect effect on intention (guilt and social norms) and to some extent also influences perceived behavioural control and attitude. This could suggest that travel by public transport is not considered to be a moral choice for the Greater Wellington residents. Instead public transport use is a mode choice influenced more by general attitudes about the service and perceived ease of use, which in turn are influenced by 
social norms, guilt and awareness of environmental problems caused by car use. Further, the strength of the influence on intention from perceived behavioural may diminish the effect from personal norms. As proposed by Abrahamse et al. (2007) willingness to reduce car use will be more affected by pro-social variables such as personal norm, when control factors are weak.

\section{Intention and behaviour}

The model shows that perceived behavioural control and attitude are the strongest predictors of intention ( $\beta=0.51$ and 0.44 , respectively). Together with personal norm, they explain $76 \%$ of variance of intention. Objective one ultimately sought to better understand the relationships between the psycho-social variables leading to public transport use. The results indicate that for the present sample, intention to use public transport rather than to drive is affected mainly by perceived behavioural control (i.e. how easy/difficult is it to take public transport rather than drive?) and attitude (i.e. what are the positive/negative consequences of using public transport rather than driving?). Intention is affected indirectly by knowledge of environmental problems, social norms and guilt which are mediated through the three predictors of intention (perceived behavioural control, attitude and personal norm).

The second objective of the study was to assess how pro-environmental intentions affect public transport use. The standardised path coefficient between intention and behaviour is high $(\beta=0.75)$ and a significant proportion of the variance of behaviour $(56 \%)$ can be explained by intention. These results support the application of the TPB because intention mediates all influencing factors leading towards behaviour, in this study public transport use. The missing $44 \%$ of the variance of behaviour may be in part due to measurement error. Behaviour was measured using self-reportedquestions, and may therefore not be as reliable as an objective behaviour measure (Armitage and Conner, 2001). The unexplained variance may also be 
accounted for situational factors that were not measured in the model. The reliability of public transport services may have been especially influential because the survey was taken during a period of disruption to many of the train services. Although public transport use remained relatively stable between 2003 and 2010, the perception of public transport reliability has decreased across all modes in the region. For example, satisfaction of reliability levels from train users dropped from 60\% in 2009 to 37\% in 2010 (Premium Research, 2010), suggesting that poor service may, in part, explain the intention-behaviour gap.

\section{Discussion}

The goal of the present study was to build on previous research assessing what psychosocial variables lead to public transport use as a specific pro-environmental behaviour. Based on the literature, it was expected that both pro-social and self-interest variables would affect public transport use, and that the variables would be mediated through intention as postulated in the TPB. The study tested two previously proposed integrated models (Bamberg \& Möser, 2007; Bamberg, et al., 2007) to examine the effects of psycho-social variables on public transport use for a sample in Greater Wellington, New Zealand.

Theoretically, the results support the environmental behaviour model proposed by Bamberg and Möser (2007). The hypothesis that elements from the self-motivated theory of planned behaviour (TPB; Ajzen, 1991) and the pro-social oriented norm-activation model (NAM; Schwartz, 1977) and value-belief-norm theory (VBN; Stern, et al., 1999) lead to proenvironmental behaviour is also confirmed. As hypothesised, intention mediates the effect of all other constructs on pro-environmental behaviour, as postulated in the TPB. Social norm is not a direct predictor of intention as stated in the TPB, but is mediated through perceived behavioural control, attitude and personal norm supporting reviews of the TPB (Kaiser 2006) and other 
studies (e.g. Wall, et al., 2007), where social norm is substituted for personal norm as a direct predictor of intention. Problem awareness indirectly affects behaviour to use public transport which is a contributing factor in Stern et al.'s (1999) VBN theory (where it is labelled adverse consequences). Building on previous studies, the results have shown that there is a theoretical justification for integrating behaviour models to determine pro-environmental behaviours.

In contrast to previous studies (e.g. Abrahamse et al., 2007; Wall, et al., 2007; Heath \& Gifford, 2002) personal norm was not found to be a significant direct predictor of intention. Personal norm was mediated by guilt (taken as a proxy of ascription of responsibility from the NAM) and also by social norms. This result is similar to that found by Bamberg et al. (2003) which was explained by the general social acceptance of the car in modern society. Given that New Zealand has the second highest calculated vehicle kilometres travelled from all OECD countries, behind the United States only (OECD, 2007), this explanation is plausible. It suggests that the present sample accepts that driving is socially acceptable and acknowledges the facts about car use damaging the environment, but do not feel morally obliged to use alternative modes. Instead the results show that people are motivated more by perceived ease of use and attitudes towards public transport which are less affected by a sense of morality and more affected by social acceptability and environmental awareness.

The significance of the psychological constructs of perceived behavioural control, attitude and personal norm, which lead to intention and behaviour, indicate the need for an integrative model approach, as proposed by Hines et al. (1986/7), when examining complex proenvironmental behaviours such as public transport use. Further to previous studies, the integrated modelling approach is perhaps even more important in transport behaviour studies. This is because the myriad of psychological barriers, including habits and structural barriers, such as 
public transport availability, that affect decisions to use public transport over driving a car make changing those decisions extremely hard (Abrahamse, et al., 2009; Fujii, 2006).

There are also several practical implications from this study. An understanding of the variables leading to public transport use can be used in policy and marketing strategies to further encourage its use, and reduce driving. Interestingly, whilst there was a strong link between problem awareness and awareness of consequences $(\beta=0.88)$, the effect of awareness of consequences was not significant on attitudes towards public transport. This suggests that the Greater Wellington sample who use a car for everyday trips do recognise the environmental effects of driving (see Table 3), but this awareness of the negative effects of driving does not influence their specific attitude. Besides strongly affecting awareness of consequences, problem awareness also indirectly affect intentions to use public transport via social norms and perceived behavioural control on one hand, and guilt and attitude on the other hand. These findings further support the importance of this VBN variable.

Perhaps contextual factors might explain some of the predicted but non-significant paths depicted in Figure 2. Using a similar model to the present study, Bamberg et al. (2007) found some support for different perceptions of public transport intention and use being explained by different social contexts. It would be interesting to test whether the model would also be supported in a more urbanised and populated region such as Auckland, New Zealand's largest city, where car use is much higher.

The perception that public transport is easy (shown through perceived behavioural control) and attitudes towards public transport (how agreeable taking public transport is over driving) were the two most important influences on intentions to use public transport. If general public opinion can be generated in favour of public transport (social norms), this may lead to the 
activation of better attitudes and greater perceived behavioural control (i.e. the perception that public transport is a pleasant mode of transport and that it is easy to use). Bamberg et al. (2007) suggested that changing public opinion may be a precondition to any intervention attempt to change behaviour. Indeed, improving the perception of the ease and convenience of public transport has been shown to encourage public transport use overseas (Brög, 2004). Increasing awareness of the problems caused by car use (problem awareness), which is strongly linked to the formation of social norms, may also be beneficial in changing attitudes towards public transport.

Given that the survey was taken during a period of train travel disruptions the responses to questions targeting attitude and perceived behaviour control may have been overly in favour of using the car instead of public transport. Therefore suggested implications should be treated with care. However, there is evidence to suggest that for policy aimed at motivating public transport use in general, and in Greater Wellington in particular, is that using pro-environmental marketing alongside strategies to improve ease and convenience (i.e. reducing travel disruptions) will be likely to have positive effects on public transport use. This result is similar to that found by Peters et al. (2011) when assessing decisions to purchase fuel-efficient vehicles. Therefore, there is evidence to suggest that the relationships between the model constructs can be drawn upon to encourage different types of pro-environmental behaviour in the transport domain.

\section{Limitations and future research}

On completion of this research some areas have been identified for improvement. The effect of habit as a psychological barrier to public transport use, although acknowledged, was not tested. Habit was added to the behaviour model in the Bamberg et al. (2007) study, measured by assessing past public transport use one year before the final study was carried out. For practical 
and time reasons this part of their study could not be replicated. Including habit as a predictor of public transport use would provide empirical evidence of the habit-behaviour link and would be useful to know in terms of policy attempting to change these engrained habits and should be included in future studies. It should also be noted that despite its advantages the online survey method used did not guarantee a representative sample of the Greater Wellington region. However, the sample was large and broadly similar to the population of the region (see Table 1). In contrast to the original research (Bamberg, et al., 2007; Bamberg \& Möser, 2007) the effect of personal norms on intention to use public transport was found to be non-significant. It was not the purpose of this study to assess the effect of personal norms on behaviour specifically, but rather to look at the total effect of psychological constructs. Future research could add to the debate on the effect of personal norms influencing transport mode choice (Abrahamse, et al., 2009; Stern, et al., 1999; Wall, et al., 2007) by using the integrated model used in this study and by Bamberg et al. (2007). Also, despite the positive link found between intention and public transport use, situational factors such as economic considerations were not specifically tested for, which might explain the intention-behaviour gap as suggested by Hines et al. (1986/7).

This study's findings suggest that more research is needed on the role of moral constructs, such as personal norm and guilt, in affecting the formation of pro-environmental norms as well as influencing pro-environmental behaviour. The role of guilt was found to be significant in the present study and in both the Bamberg and Möser and Bamberg et al. (2007) studies, but according to Bamberg et al. (2007) only two other studies have examined the role of guilt in forming pro-environmental norms. Further, Bamberg et al. (2007) found that in different social contexts, the roles of guilt and personal norm changed. More research is needed to assess 
whether this result is due to contextual factors, such as country, sample size, sampling method, or theoretical considerations.

The results are mainly in line with findings from the original model proposed by Bamberg and Möser (2007). The hypothesis that pro-environmental behaviour can be motivated by both pro-social interests as well as self-interests is confirmed. The psychological approach has highlighted the importance of specific constructs in the decision making process to use public transport. Significantly, if perceptions of public transport are improved through social norms, perceived behavioural control and attitude, public transport use may be encouraged. In other words interventions to increase public transport patronage and decrease car use should focus on enhancing: positive public opinion of public transport (social norms), the perception that travel on public transport is easy (perceived behavioural control) as well as more pleasant or good (attitude) by making improvements on the ground as well enhancing the customer experience.

\section{Acknowledgements}

Camilla Morley would like to thank the Centre for Sustainable Cities and Greater Wellington Regional Council who provided scholarship funding for the original Masters thesis, without which this paper would not have been possible.

\section{References}

Abrahamse, W., Steg, L., Gifford, R., \& Vlek, C. (2009). Factors influencing car use for commuting and the intention to reduce it: A question of self-interest or morality? Transportation Research Part F-Traffic Psychology and Behaviour, 12, 317-324.

Ajzen, I. (1991). The theory of planned behavior. Organizational Behavior and Human Decision Processes, 50, 179-211. 
Psycho-social determinants of public transport use 28

Armitage, C. J., \& Conner, M. (2001). Efficacy of the theory of planned behaviour: A metaanalytic review. The British Journal of Social Psychology, 40, 471-499.

Babakus, E., Ferguson, C. E., Jr., \& Jöreskog, K. G. (1987). The sensitivity of confirmatory maximum likelihood factor analysis to violations of measurement scale and distributional assumptions. Journal of Marketing Research, 24, 222-228.

Bamberg, S., Hunecke, M., \& Blöbaum, A. (2007). Social context, personal norms and the use of public transportation: Two field studies. Journal of Environmental Psychology, 27, 190203.

Bamberg, S., \& Möser, G. (2007). Twenty years after Hines, Hungerford, and Tomera: A new meta-analysis of psycho-social determinants of pro-environmental behaviour. Journal of Environmental Psychology, 27, 14-25.

Bamberg, S., \& Schmidt, P. (2003). Incentives, morality, or habit? Predicting students' car use for university routes with the models of Ajzen, Schwartz, and Triandis. Environment and Behavior, 35, 264.

Boldero, J. (1995). The prediction of household recycling of newspapers - the role of attitudes, intentions, and situational factors. Journal of Applied Social Psychology, 25, 440-462.

Brög, W., Erl, E., \& Mense, N. (2004). Individualised marketing: Changing travel behaviour for a better environment. Communicating Environmentally Sustainable Transport-The Role of Soft Measures (pp. 83-97). Paris: OECD.

Cialdini, R. B. (2007). Descriptive social norms as underappreciated sources of social control. Psychometrika, 72, 263-268.

Dawes, R. M., \& Messick, D. M. (2000). Social Dilemmas. International Journal of Psychology, $35,111-116$. 
De Groot, J. I. M., \& Steg, L. (2009). Morality and prosocial behavior: the role of awareness, responsibility, and norms in the norm activation model. Journal of Social Psychology, $149,425-449$.

Diamantopoulos, A., \& Siguaw, J. A. (2000). Introducing LISREL: a guide for the uninitiated. London: Sage Publications.

Eriksson, L., Garvill, J., \& Nordlund, A. M. (2008). Interrupting habitual car use: The importance of car habit strength and moral motivation for personal car use reduction. Transportation Research Part F: Traffic Psychology and Behaviour, 11, 10-23.

Field, A. (2005). Discovering statistics using SPSS (2 ${ }^{\text {nd }}$ ed.). Los Angeles; London: Sage Publications.

Fisher, G. W., Rolfe, K. A., Kjellstrom, T., Woodward, A., Hales, S., Sturmam, A. P. (2002). Health effects due to motor vehicle air pollution in New Zealand. Wellington. Retrieved $10^{\text {th }}$ March, 2010, from www.transport.govt.nz/assets/PDFs/health-effects-of-vehicleemissions.pdf.

Fujii, S. (2006). Environmental concern, attitude toward frugality, and ease of behavior as determinants of pro-environmental behavior intentions. Journal of Environmental Psychology, 26, 262-268.

GWRC. (2010). Wellington regional land transport strategy 2010-40. Wellington: Greater Wellington Regional Council.

Hair, J. F., Black, W. C., Babin, B. J., Anderson, R. E., \& Tatham, R. L. (2006). Multivariate data analysis. New Jersey: Pearson Education Inc. 
Harland, P., Staats, H., \& Wilke, H. A. M. (1999). Explaining proenvironmental intention and behavior by personal norms and the theory of planned behavior. Journal of Applied Social Psychology, 29, 2505-2528.

Heath, Y., \& Gifford, R. (2002). Extending the theory of planned behaviour: Predicting the use of public transport. Journal of Applied Social Psychology, 32, 2154-2189.

Hines, J. M., Hungerford, H. R., \& Tomera, A. N. (1986/7). Analysis and synthesis of research on responsible environmental behavior: A meta-analysis. Journal of Environmental Education, 18, 1-8.

Hooper, V., \& Zhou, Y. (2007). Addictive, dependent, compulsive? A study of mobile phone usage. Paper presented at the $20^{\text {th }}$ Bled eConference: Merging and emerging technologies, processes and institutions, Bled, Slovenia.

Hu, L.-T., \& Bentler, P. M. (1999). Cutoff criteria for fit indexes in covariance structure analysis: Conventional criteria versus new alternatives. Structural Equation Modeling: A Multidisciplinary Journal, 6, 1-55.

Hunecke, M., Blobaum, A., Matthies, E., \& Hoger, R. (2001). Responsibility and environment ecological norm orientation and external factors in the domain of travel mode choice behavior. Environment and Behavior, 33, 830-852.

IPCC. (2007). Climate change 2007: Synthesis report. In R. K. Pachauri \& A. Reisinger (Eds.), Contribution of Working Groups I, II and III to the Fourth Assessment Report of the Intergovernmental Panel on Climate Change. Geneva. Retrieved 25 th March, 2011, from http://www.ipcc.ch/publications_and_data/publications_ipcc_fourth_assessment_report_s ynthesis report.htm 
Jakobsson, C., Fujii, S., \& Gärling, T. (2002). Effects of economic disincentives on private car use. Transportation, 29, 349-370.

Johansson, M., V., Heldt, T., \& Johansson, P. (2006). The effects of attitudes and personality traits on mode choice. Transportation Research Part A: Policy and Practice, 40, 507525.

Joireman, J. A., Van Lange, P. A. M., \& Van Vugt, M. (2004). Who cares about the environmental impact of cars? Those with an eye toward the future. Environment and Behavior, 36, 187.

Kaiser, F. G., \& Gutscher, H. (2003). The proposition of a general version of the theory of planned 31ehaviour: Predicting ecological 31ehaviour. Journal of Applied Social Psychology, 33, 586-603.

Kaiser, F. G. (2006). A moral extension of the theory of planned behavior: Norms and anticipated feelings of regret in conservationism. Personality and Individual Differences, $41,71-81$.

Klöckner, C. A., \& Blöbaum, A. (2010). A comprehensive action determination model: Toward a broader understanding of ecological behaviour using the example of travel mode choice. Journal of Environmental Psychology, 30, 574-586.

Lake, B., Milfont, T. L., \& Gavin, M. C. (in press). The relative influence of psycho-social factors on urban edible gardening. New Zealand Journal of Psychology, 40, 56-67.

Limtanakool, N., Dijst, M., \& Schwanen, T. (2006). The influence of socioeconomic characteristics, land use and travel time considerations on mode choice for medium- and longer-distance trips. 
Manfreda, K. L., \& Vehovar, V. (2008). Internet surveys. In E. D. de Leeuw, J. J. Hox \& D. A. Dillman (Eds.), International handbook of survey methodology. New York: Taylor \& Francis Group, LLC.

Matthies, E., Kuhn, S., \& Klöckner, C. A. (2002). Travel mode choice of women: The result of limitation, ecological norm, or weak habit? Environment and Behavior, 34, 163-177.

May, A. D., Kelly, C., \& Shepherd, S. (2006). The principles of integration in urban transport strategies. Transport Policy, 13, 319-327.

Milfont, T. L. (2010). Global warming, climate change and human psychology. In V. CorralVerdugo, C. H. García-Cadena \& M. Frías-Arment (Eds.), Psychological approaches to sustainability: Current trends in theory, research and practice. (pp. 19-42). New York: Nova Science Publishers.

Milfont, T. L., Abrahamse, W., \& McCarthy, N. (2011). Spatial and temporal biases in assessments of environmental conditions in New Zealand. New Zealand Journal of Psychology, 40, 56-67.

Milfont, T. L., Sibley, C. G., \& Duckitt, J. (2010). Testing the moderating role of the components of norm activation on the relationship between values and environmental 32ehaviour. Journal of Cross-Cultural Psychology, 41, 124-131.

Morley, C. (2011). Motivating public transport use: Travel behaviour and integrated ticketing for Greater Wellington. Masters thesis (not published), Victoria University of Wellington, Wellington.

Mueller, D. J. (1986). Measuring social attitudes: A handbook for researchers and practitioners. New York: Teachers College Press. 
Nankervis, M. (1999). The effect of weather and climate on bicycle commuting. Transportation Research Part A: Policy and Practice, 33, 417-431.

OECD (2007). OECD environmental performance reviews New Zealand. Paris: OECD Publishing.

Ostrom, E. (2000). Collective action and the evolution of social norms. The Journal of Economic Perspectives, 14, 137-158.

Pallant, J. (2010). SPSS survival manual (4 ${ }^{\text {th }}$ ed.). Crows Nest, NSW: Allen \& Unwin.

Parsons, C. (2007). Web-based surveys: Best practices based on the research literature. Visitor Studies, 10, 13-33.

Peters, A., Gutscher, H., \& Scholz, R. W. (2011). Psychological determinants of fuel consumption of purchased new cars. Transportation Research Part F: Traffic Psychology and Behaviour, 14, 229-239.

Premium Research. (2008). Annual Public Transport Satisfaction Monitor 2008 Market Research Report. Wellington: Greater Wellington Regional Council.

Premium Research. (2009). Greater Wellington Regional Council Annual Public Transport Satisfaction Monitor 2009 Report. Wellington: Greater Wellington Regional Council.

Premium Research. (2010). Annual public transport satisfaction monitor 2010 report. Wellington: Greater Wellington Regional Council.

Reips, U.-D. (2006). Web-based methods. In M. Eid \& E. Diener (Eds.), Handbook of multimethod measurement in psychology (pp. 73-85). Washington, DC: American Psychological Association. 
Riva, G., Teruzzi, T., \& Anolli, L. (2003). The use of the internet in psychological research: Comparison of online and offline questionnaires. CyberPsychology and Behavior, 6, 7380.

Schwartz, S. (1977). Normative influences on altruism. In L. Berkowitz (Ed). Advances in experimental social psychology, 10, 222-279.

Shapiro, R. J., Hassett, K. A., \& Arnold, F. A. (2002). Conserving energy and preserving the environment: The role of public transportation. A report commissioned by the American public transport association. Retrieved $24^{\text {th }}$ November, 2009, from http://74.125.155.132/scholar?q=cache:IjJ5wG580gJ:scholar.google.com/transport + shapiro $+2002 \& h l=e n \& a s ~ s d t=2000$

Staats, H. (2004). Pro-environmental attitudes and behavioral change. In C. Spielberger (Ed.), Encyclopedia of Applied Psychology (Vol. 3, pp. 127-135). New York: Elsevier

Statistics New Zealand. (2006). Meshblock dataset. Retrieved $10^{\text {th }}$ November 2010, from http://www.stats.govt.nz/Census/2006CensusHomePage/MeshblockDataset.aspx? $\underline{\text { tab=Download }}$

Steg, L., Dreijerink, L., \& Abrahamse, W. (2005). Factors influencing the acceptability of energy policies: A test of VBN theory. Journal of Environmental Psychology, 25, 415-425.

Stern, P. C. (2000). Toward a coherent theory of environmentally significant behavior. The Journal of Social Issues, 56, 407-424.

Stern, P. C., Dietz, T., Abel, T., Guagnano, G. A., \& Kalof, L. (1999). A value belief norm theory of support for social movements: The case of environmental concern. Human Ecology Review, 6, 81-97. 
Swim, J., Clayton, S., Doherty, T., Gifford, R., Howard, G., Reser, J., et al. (2009). Psychology and global climate change: Addressing a multi-faceted phenomenon and set of challenges. A report by the American Psychological Association's task force on the interface between psychology and global climate change. Retrieved $7^{\text {th }}$ June, 2010, from http://www.apa.org/science/about/publications/climate-change.aspx

Van Vugt, M., Meertens, R. M., \& van Lange, P. A. M. (1995). Car versus public transportation? The role of social value orientations in a real-life social dilemma. Journal of Applied Social Psychology, 25, 258-278.

Verplanken, B., Aarts, H., van Knippenberg, A., \& Moonen, A. (1998). Habit, information acquisition, and the process of making travel mode choices. British Journal of Social Psychology, 37, 111-128.

Wall, R., Devine-Wright, P., \& Mill, G. (2007). Comparing and combining theories to explain proenvironmental intentions. Environment and Behavior, 39, 731-753. 
Table 1. Socio-demographic variables of the sample $(N=359)$

\begin{tabular}{|c|c|c|c|c|c|}
\hline Variable & $(\%)$ & Variable & $(\%)$ & Variable & $(\%)$ \\
\hline GW Area & & Employment & & Household & \\
\hline $\begin{array}{l}\text { Kapiti } \\
\text { Coast }\end{array}$ & $5.0 \%(8.9 \%)$ & Full time & $83.4 \%$ & Single occupier & $9.5 \%$ \\
\hline Masterton & $0.3 \%(5.2 \%)$ & Part time & $8.1 \%$ & Group living together & $15.6 \%$ \\
\hline $\begin{array}{l}\text { South } \\
\text { Wairarapa }\end{array}$ & $0.6 \%(2.1 \%)$ & Not working & $8.4 \%$ & $\begin{array}{l}\text { Couple - no children } \\
\text { at home }\end{array}$ & $36.0 \%$ \\
\hline $\begin{array}{l}\text { Lower } \\
\text { Hutt }\end{array}$ & $22.6 \%(22.1 \%)$ & Income (NZ\$) & & $\begin{array}{l}\text { Family - pre-school } \\
\text { children }\end{array}$ & $11.7 \%$ \\
\hline $\begin{array}{l}\text { Wellington } \\
\text { City }\end{array}$ & $54.3 \%(36.4 \%)$ & $0-20,000$ & $9.8 \%$ & $\begin{array}{l}\text { Family - school } \\
\text { children }\end{array}$ & $17.3 \%$ \\
\hline Porirua & $10.3 \%(10.7 \%)$ & $20,001-50,000$ & $19.4 \%$ & $\begin{array}{l}\text { Family - adult } \\
\text { children }\end{array}$ & $9.8 \%$ \\
\hline $\begin{array}{l}\text { Upper } \\
\text { Hutt }\end{array}$ & $7.0 \%(8.5 \%)$ & $50,001-70,000$ & $24.9 \%$ & Public transport use ${ }^{a}$ & \\
\hline Median age & $39(36)$ & $70,001-100,000$ & $28.0 \%$ & Regular users & $49 \%$ \\
\hline Sex & & $100,000+$ & $17.8 \%$ & Occasional users & $22.6 \%$ \\
\hline Male & $52.7 \%(47.3 \%)$ & & & Light users & $23.7 \%$ \\
\hline Female & $47.3 \%(51.5 \%)$ & & & Non-users & $4.7 \%$ \\
\hline
\end{tabular}

Note: Values are percentage values except the Age variable where the median age is shown.

Italicised numbers in brackets represent demographic data from the 2006 census figures for Greater Wellington (Statistics New Zealand, 2006). ${ }^{\text {a }}$ Public transport use categories were classified according to how often participants used public transport: Regular users $=3$ or more days a week; Occasional users = between twice a week and once a fortnight; Light users = once a month or less; Non-users $=$ never. 
Table 2. Measures used to predict public transport use behaviour

\section{Construct Items}

1 Problem awareness

PA1 - Car use is one of the main global environmental problems.

(PA)

(Cronbach's

PA2 - There is an urgent need to do something about the environmental

alpha $=$

$0.74)$ pollution caused by car use.

2 Awareness of AC1 - When I drive, exhaust gases are emitted which have a negative consequences effect on the global climate system.

(AC) AC2 - When I drive, exhaust gases are emitted which endanger other (Cronbach's people's health.

alpha $=\quad \mathrm{AC} 3 *-\mathrm{I}$ do not think my personal car use has a negative impact on the 0.75) living quality of future generations.

3 Social norms SN1 - People who are close to me (e.g. friends and family) would support (SN) my decision to use public transport instead of the car for everyday trips in (Cronbach's Greater Wellington.

alpha $=0.52) \quad \mathrm{SN} 2-$ People who are close to me (e.g. friends and family) think I should use public transport more and drive less for everyday trips in Greater Wellington.

SN3 $*^{+}$- Most people I know don't care if I drive or take public transport for everyday trips here in Greater Wellington.

SN4*+ - Most people who are important to me would support me using the car for everyday trips in Greater Wellington.

4 Guilt (G) G1* - When I use the car I do not feel guilty in terms of the environment. (Cronbach's G2 - If I always used my car, I would have a bad environmental alpha $=0 \quad$ conscience.

.81) G3 - Taking into account that pollutants from car use threaten other people's health, I would have a bad conscience when using the car. 
5 Perceived PBC1 - It would be (impossible / possible) for me to use public transport behavioural instead of the car for everyday trips in Greater Wellington.

control PBC2 - I am (unsure / sure) that in the next few days I can use public

(PBC) transport instead of the car for everyday trips in Greater Wellington.

(Cronbach's PBC3 - It is mostly up to me whether I use public transport instead of the

$a l p h a=0.72) \quad$ car for everyday trips here in Greater Wellington.

PBC4 - I have (no / full) freedom of choice to use public transport rather than drive for everyday trips in Greater Wellington.

6 Attitude ATT1* - I would not like to use public transport instead of the car for (ATT) everyday trips in Greater Wellington.

(Cronbach's ATT2 - Using public transport instead of the car for everyday trips in

alpha $=0.78) \quad$ Greater Wellington would be (unpleasant / pleasant) for me.

ATT3 - Using public transport instead of the car for everyday trips in Greater Wellington would be (good / bad) for me.

7 Personal PN1* - According to my own values and principles I do not feel obligated norm (PN) to use public transport instead of driving.

(Cronbach's PN2 - Regardless of what other people do, I feel obligated to use public alpha $=0.84) \quad$ transport because of my own values and principles.

PN3 - I feel obligated to use public transport for environmental reasons.

8 Intention INT1 - It is (unlikely / likely) that in the next few weeks I will use public (INT) transport for everyday trips in Greater Wellington.

(Cronbach's INT2 - My intention to use public transport in the next few weeks instead alpha $=0.91)$ of the car for trips within Greater Wellington is (weak / strong).

INT3 - I intend to use public transport instead of the car in the next few weeks for everyday trips around Greater Wellington. 

9 Behaviour $\quad$ BEH1* - On average how often do you use public transport (bus, train, (BEH) ferry or cable car) within the Greater Wellington region? (Scaled 1-7, from '5 or more days a week' to 'Never')
- $\quad \mathrm{BEH} 2$ - Indicate below if you would like to go into the draw to win a $\$ 100$ public transport voucher. (Yes / No) BEH3 - Ratio of mode used for the 4 everyday trips (work/study, food shopping, recreation facilities, and sport activities) from 0 (none by public transport) to 1.0 (all by public transport).

$\overline{\text { Note. Plus (+) sign indicates new items, and asterisk }\left(^{*}\right) \text { sign indicates reverse-scored items. SN4 }}$ and PBC4 were added after the pilot study due to initial low Cronbach's alpha values. SN3 and PBC4 were later removed from the SEM because of weak factor loadings (discussed in the Results section). 
Table 3. Means (M), standard deviations (SD) and one-sample $t$-test results for the constructs in the integrated environmental behaviour model as used in the present study

\begin{tabular}{llll}
\hline Construct & $\boldsymbol{M}$ & $\boldsymbol{S D}$ & $\boldsymbol{t}$ \\
\hline Problem awareness & 3.45 & 0.90 & $9.50^{* * *}$ \\
Awareness of consequences & 3.79 & 0.73 & $20.34 * * *$ \\
Social norm & 2.88 & 0.64 & $-3.675^{* * *}$ \\
Guilt & 2.98 & 0.97 & -.308 \\
Perceived behavioural control & 3.74 & 0.84 & $16.82^{* * *}$ \\
Attitude & 3.24 & 0.92 & $5.00^{* * *}$ \\
Personal norm & 2.94 & 1.06 & -1.025 \\
Intention & 3.13 & 1.32 & 1.82 \\
Public transport frequency & 3.04 & 2.01 & $9.01 * * *$ \\
Trip ratio $^{\mathrm{a}}$ & 0.14 & 0.16 & $42.24 * * *$ \\
\hline
\end{tabular}

Note. $N=359$. Constructs were measured on a scale from 1 to 5 with a mid-point of $3{ }^{\text {a }}{ }^{\text {These }}$ variables were measured on different scales. Public transport frequency was measured on a scale from 1 = 'high public transport use' to 7 = 'no use' (reversed coded for analysis) with a midpoint of 4 . Ratio of the four everyday trips taken by public transport was measured on a scale from $0=$ 'no use' to $1=$ 'always use', with a mid-point of 0.5 . *** $p<.001$ (two-tailed). 
Table 4. Results of the confirmatory factor analysis testing the reliability of the measures used for each construct in the model

\begin{tabular}{|c|c|c|c|}
\hline & Construct & Item & $\lambda$ \\
\hline \multirow[t]{3}{*}{1} & Problem & PA1 & 0.72 \\
\hline & awareness & PA2 & 0.84 \\
\hline & & PA3 & 0.56 \\
\hline \multirow[t]{3}{*}{2} & Awareness of & $\mathrm{AC} 1$ & 0.74 \\
\hline & consequences & $\mathrm{AC} 2$ & 0.68 \\
\hline & & $\mathrm{AC} 3$ & 0.71 \\
\hline \multirow[t]{4}{*}{3} & Social norm & SN1 & 0.54 \\
\hline & & SN2 & 0.50 \\
\hline & & SN3 & 0.51 \\
\hline & & SN4 & 0.39 \\
\hline \multirow[t]{3}{*}{4} & Guilt & G1 & 0.69 \\
\hline & & G2 & 0.77 \\
\hline & & G3 & 0.83 \\
\hline \multirow[t]{4}{*}{5} & Perceived & $\mathrm{PBC} 1$ & 0.71 \\
\hline & behavioural & $\mathrm{PBC} 2$ & 0.92 \\
\hline & control & PBC3 & 0.25 \\
\hline & & PBC4 & 0.44 \\
\hline \multirow[t]{3}{*}{6} & Attitude & ATT1 & 0.66 \\
\hline & & ATT2 & 0.75 \\
\hline & & ATT3 & 0.81 \\
\hline \multirow[t]{3}{*}{7} & Personal & PN1 & 0.74 \\
\hline & norm & PN2 & 0.80 \\
\hline & & PN3 & 0.84 \\
\hline \multirow[t]{3}{*}{8} & Intention & INT1 & 0.91 \\
\hline & & INT2 & 0.89 \\
\hline & & INT3 & 0.84 \\
\hline
\end{tabular}




\begin{tabular}{|c|c|c|c|}
\hline & Behaviour & BEH1 & 0.72 \\
\hline & & $\mathrm{BEH} 2^{\mathrm{a}}$ & 0.28 \\
\hline & & BEH3 & 1.00 \\
\hline
\end{tabular}

Note. $\mathrm{N}=359 . \lambda=$ standardized factor loadings. ${ }^{a} \mathrm{BEH} 2$ was a dichotomous measure, which might explain the low $\lambda$ value. 
Table 5. Goodness-of-fit indices for the competing models

\begin{tabular}{llllllll}
\hline Model & $\chi^{2}$ & $\mathrm{df}$ & $\chi^{2} / \mathrm{df}$ & RMSEA & SRMR & CFI & NNFI \\
\hline Model 1a (from Bamberg and Möser, 2007) & 590.71 & 303 & 1.95 & 0.052 & 0.056 & 0.98 & 0.97 \\
Model 1b (Model 1a minus non-significant paths) & 599.60 & 311 & 1.93 & 0.051 & 0.056 & 0.98 & 0.97 \\
Model 2a (from Bamberg et al., 2007) & 592.94 & 306 & 1.94 & 0.051 & 0.056 & 0.98 & 0.97 \\
Model 2b (Model 2a minus non-significant paths) & 673.78 & 312 & 2.16 & 0.057 & 0.063 & 0.97 & 0.97 \\
\hline
\end{tabular}

Note. The model fit indices exclude PBC3 and SN4 which were removed to decrease measurement error in the model and improve model fit. $\chi^{2}=$ Chi-square, $\mathrm{df}=$ degrees of freedom, $\chi^{2} / \mathrm{df}=$ Chi-square divided by degrees of freedom, RMSEA $=$ root mean square error of approximation, $\mathrm{SRMR}=$ standardised root-mean square residual, $\mathrm{CFI}=$ comparative fit index, NNFI $=$ non-normed fit index. 


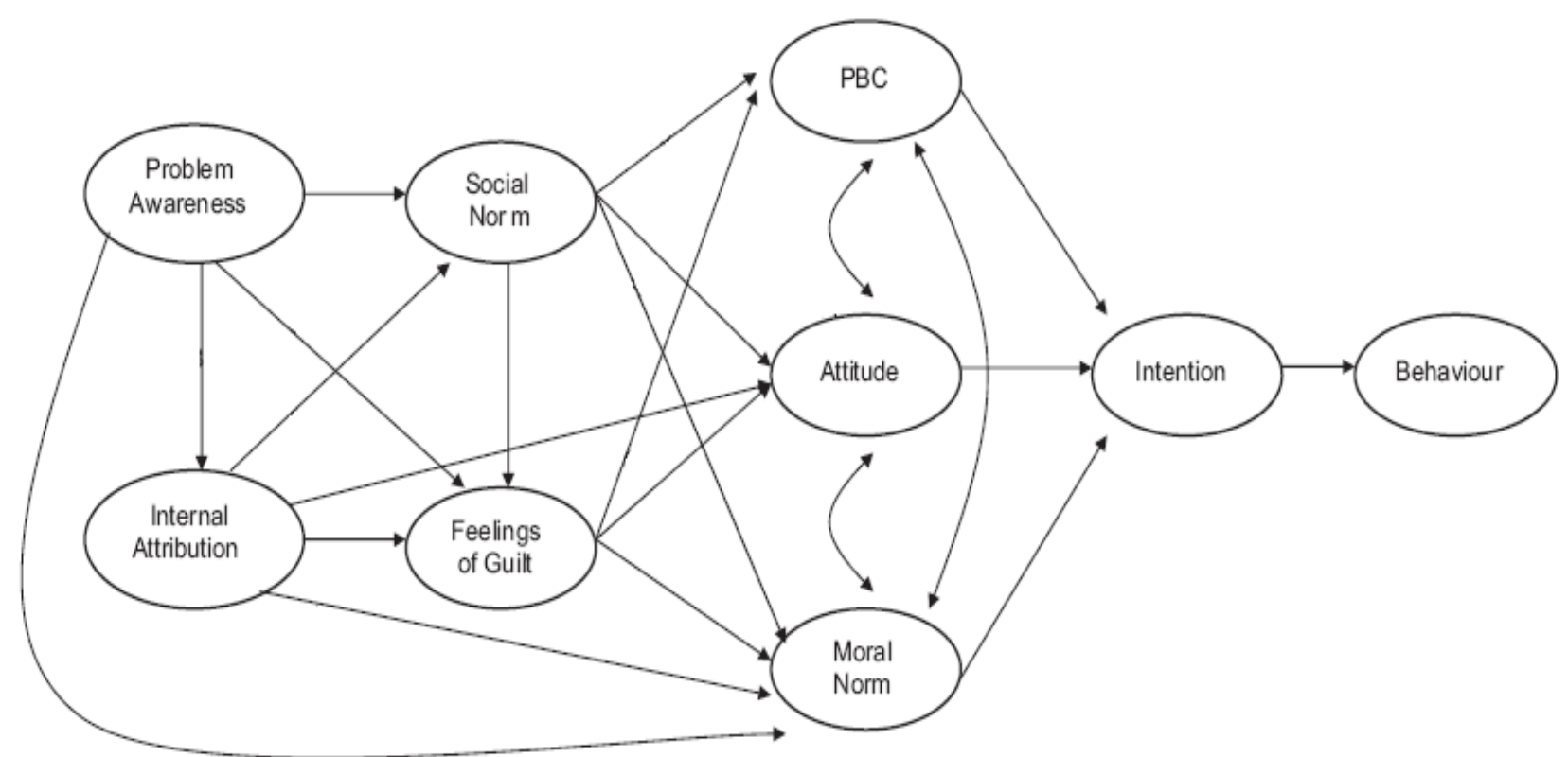

Figure 1. Meta-analytic structural equation model explaining pro-environmental intention and behaviour proposed by Bamberg and Möser (2007)

Note PBC $=$ perceived behavioural control. Internal attribution $=$ awareness of consequences. Moral norm $=$ personal norm. 


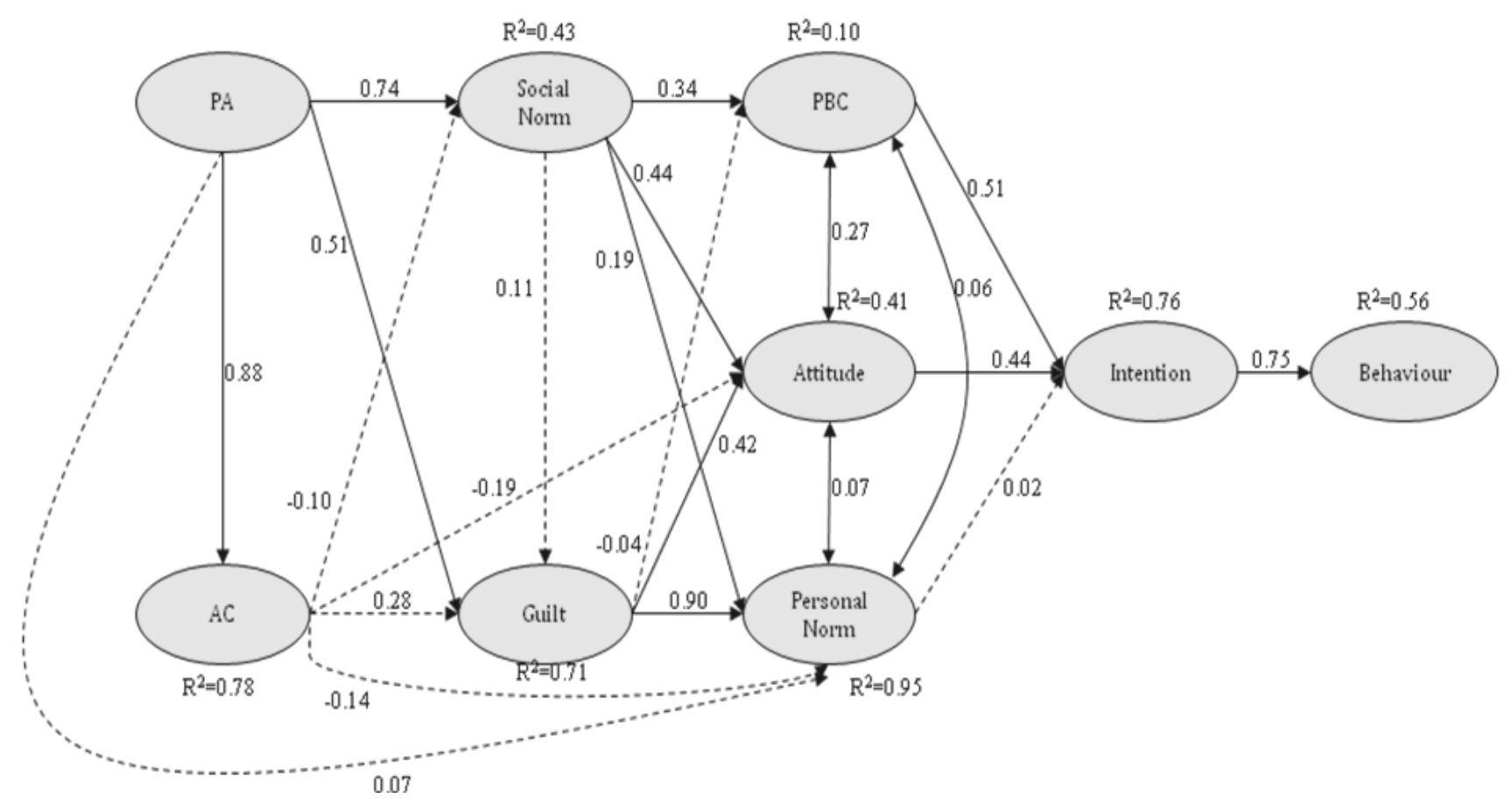

Figure 2. The results of the integrated environmental behaviour model

Note: $\mathrm{PA}=$ Problem Awareness, $\mathrm{AC}=$ Awareness of Consequences and $\mathrm{PBC}=$ Perceived Behavioural Control. Single headed arrows are standardised path coefficients, double headed arrows are correlations and $\mathrm{R}^{2}$ are the explained variances. Dashed lines indicate non-significant paths $(\mathrm{t}<1.96, \mathrm{p}>.05)$. 